\title{
Three port versus four port laparoscopic cholecystectomy- a prospective study
}

\author{
Wilkinson TRV ${ }^{1}$, Mehrotra $P^{2}$, Bansod P ${ }^{3}$, Akhtar $M^{4}$ \\ ${ }^{1}$ Dr. TRV Wilkinson, Associate Professor, ${ }^{2}$ Dr. Pranav Mehrotra, Junior Resident, ${ }^{3}$ Dr. Prasad Y. Bansod, Senior \\ Resident, ${ }^{4}$ Dr. Murtaza Akhtar, Prof. \& HOD, all authors are affiliated with Department of Surgery, NKP Salve Institute \\ of Medical Sciences \& Research Centre, Nagpur, Maharashtra, INDIA.
}

Address for Correspondence: Dr. Prasad Y. Bansod, 37. Samta Nagar, North Ambazari Road, Nagpur, Email: rabbu7288@gmail.com

\begin{abstract}
Introduction: Cholelithiasis is the most common and important cause of biliary tract disease. In today's world, laparoscopic cholecystectomy is the gold standard treatment for gallstones. Decrease in the size or number of ports provide better results in laparoscopic cholecystectomy. Objective: We aim the study to find out feasibility of three port lap cholecystectomy over four port lap cholecystectomy regarding post-op pain, duration of surgery, conversion rate, hospital stay and complications. Materials \& Methods: Patients who fulfilled the inclusion criteria were included. 76 patients enrolled for the study and divided into two groups as 3 port and 4 port. Surgical preformed assessment proforma used to collect the data. Results: The mean age of the studied patients was 46.38 years with female preponderance. The Mean operative time for three ports was 66.90 minutes and for four ports it was 75.45 minutes. Mean duration of postoperative stay for three port was 4.66 and for the conventional group it was 5.30. Conclusion: Patients who underwent the three port technique had a lesser hospital stay compared to patients who underwent the conventional 4 port technique. Patients had less postoperative pain, lesser requirement of analgesics in three port group. 2 patients from the 4 port group had fever 48 hours after surgery.
\end{abstract}

Keywords: Cholelithiasis, Laparoscopic cholecystectomy, three port lap cholecystectomy, four port lap cholecystectomy, reduced port surgery

\section{Introduction}

Cholelithiasis is the most common and important cause of biliary tract disease [1]. It has a wide range of clinical features ranging from asymptomatic stage to highly morbid gangrenous cholecystitis and gall stone pancreatitis. Biliary pancreatitis and Choledocholithiasis are the known complications of gall stone disease.

Surgical management of gall stone disease is cholecystectomy. Today laparoscopic cholecystectomy is the gold standard treatment for gallstones and the commonest operation performed worldwide [2-3] with varied advantages. Any decrease in the size or number of stab incisions (ports) may provide better results

Manuscript received: $7^{\text {th }}$ March 2017

Reviewed: $15^{\text {th }}$ March 2017

Author Corrected: $22^{\text {nd }}$ March 2017

Accepted for Publication: $31^{\text {st }}$ March 2017 added to the advantages of laparoscopic cholecystectomy. Some surgeons argue that smaller is not necessarily better [4]. While many others proved that reducing the number and size of port incisions have more favourable results [5-9]. Various port site complications are reduced as the numbers of ports reduce. We aim to find out feasibility of three port lap cholecystectomy over four port lap cholecystectomy regarding post-op pain, duration of surgery, conversion rate, hospital stay and complications.

\section{Materials and Methods}

The present study was a hospital based longitudinal study carried out in a tertiary care teaching hospital for a two year period. A total of 76 cases were recruited in this study based on inclusion and exclusion criteria. 
All patients undergoing laparoscopic cholecystectomy from August 2014 to October 2016 who fulfilled the inclusion criteria were included. All patients presenting with symptomatic gall bladder disease, Cholelithiasis without Choledocholithiasis and with no contraindication for general anaesthesia were included in the study. Data recorded included demographic information, past medical history, indication for operation, duration of operation, reason for conversion and post-operative complications.

\section{Inclusion criteria}

- All patients with symptomatic gall stone disease (Cholelithiasis, acute \& chronic cholecystitis).

- Patients presenting with acalculous cholecystitis.

- $\quad$ Age $>18$ years

- American Society for Anaesthesiology (ASA) class I and class II patients

\section{Exclusion criteria}

- Choledocholithiasis,

- Carcinoma of gall bladder,

- Perforated gall bladder

- Previous abdominal surgeries

- Anaesthetically unfit for laparoscopic surgeries.

Using a pre-prepared proforma various demographic \& clinico-radiological factors were recorded. Clinical examination and ultrasound was done for all patients. A routine pre-anesthetics check-up was done. A fully explained well informed consent was taken with explanation of risk of conversion to open cholecystectomy. Various Co-morbid conditions were classified as per the American society of anaesthesiology classification. Operating time, hospital stay, post-operative pain, analgesic requirement and complications were noted.

The patients recruited to the study underwent two types of surgical intervention. The patients were admitted to six surgical units. Of them, those admitted in one of the units where researcher was posted carried out 3 port laparoscopic cholecystectomy while all the other units did conventional laparoscopic cholecystectomy. All patients were operated under general anaesthesia with inhalation and intravenous agents and endotracheal intubation. Surgeons with grade of senior lecturer and above with fellowship in laparoscopy performed the laparoscopic cholecystectomy.

\section{Surgical technique}

1. Conventional Laparoscopic cholecystectomyPerformed with standard four port American technique or European technique.

2. Three port Laparoscopic cholecystectomy- Instead of placing 4 ports, 3 ports are placed. The port used for Gallbladder retraction was avoided and rest of the procedure carried out in the same manner possible.

Bleeding during surgery [10] was graded as:

Minimal - if pulse rate remains $<100 /$ min without any blood pressure changes.

Moderate - if tachycardia occurs $>100 /$ min without any blood pressure changes.

Severe - if tachycardia occurs $>100 /$ min with a greater than $10 \mathrm{mmHg}$ of drop in blood pressure.

The operating surgeon described the access to peritoneal cavity as easy or difficult [11]

\section{Post-operative evaluation and assessment}

- The time required for surgery was noted from time of insertion of umbilical port to removal of all ports and skin closure.

- If converted to open method, the cause of conversion, step at which converted and time after which conversion was done, were noted.

- Ryle's tube was removed immediately after surgery in all cases.

- Patients were kept nil by mouth till return of the bowel sounds.

- All patients were ambulated as early as possible.

- Drains when kept were removed if output was <10 cc. with no bile leak.

- Stitches were removed on 10th post-operative day.

- Complications directly related to the surgical technique were graded according to Clavien's classification

- Hospital Stay: Defined as the duration from operative day till suture removal.

The degree of difficulty of the operation was assessed by following factors --

1. Obesity (BMI) $<30$ - less prone for complications $\&>30$ - more prone for complications

2. Adhesions (frozen calots triangle)

3. Anatomical variations

4. Previous surgery 
5. GB wall thickness variation as seen in empyema, cholesterosis, recurrent cholecystitis

6. Bleeding

7. Fatty liver

Statistical analysis- The data was presented as mean, standard deviation, range and percentage for descriptive statistics of age, gender and clinical manifestations.
Comparison of parameters between conventional laparoscopic cholecystectomy and three port laparoscopic cholecystectomy was done using "student t-test" for continuous variables and "chi square test" or "Fisher exact test" for categorical variables. The statistical software used in the analysis was SPSS version 20, EPI Info software version 7. Statistical significance was set at $\mathrm{P}<0.05$.

\section{Results}

76 patients were evaluated undergoing conventional laparoscopic and three port laparoscopic cholecystectomy. The patients belonged to various surgical units and full details of the patients were recorded in the proforma. Observations and analysis of all the parameters were studied. Out of the 76 patients, 55 underwent conventional laparoscopic surgery and 21 underwent three port laparoscopic cholecystectomy.

Most of the patients under our study to undergo laparoscopic cholecystectomy were between $3^{\text {rd }}$ and $4^{\text {th }}$ decade of life. Youngest patient was 21 years old and oldest one was of 68 years (Table 1).

Table-1: Showing Age distribution.

\begin{tabular}{|c|c|c|c|}
\hline Age(years) & $\mathbf{3}$ port & 4 port & Number of patients \\
\hline $11-20$ & 0 & 0 & 0 \\
\hline $21-30$ & $1(4.7 \%)$ & $8(14.5 \%)$ & 13 \\
\hline $31-40$ & $8(38.1 \%)$ & $5(9.1 \%)$ & 29 \\
\hline $41-50$ & $8(38.1 \%)$ & $21(38.1 \%)$ & 13 \\
\hline $51-60$ & 0 & $13(23.6 \%)$ & 12 \\
\hline $61-70$ & $4(19 \%)$ & $8(14.5 \%)$ & $\mathbf{7 6}$ \\
\hline Total & $\mathbf{2 1}$ & $\mathbf{5 5}$ & 9 \\
\hline
\end{tabular}

Of the 76 patients who underwent laparoscopic cholecystectomy, ratio of male to female with Gall bladder disease was 1:2.61. The observed sex distribution shows that the gall bladder diseases have a higher frequency in female than in males. (Table 2)

Table-2: Showing Gender distribution.

\begin{tabular}{|c|c|c|c|}
\hline Sex & 3 port & 4 port & Total \\
\hline Male & $6(28.57)$ & $16(29.09)$ & 22 \\
\hline Female & $15(71.43)$ & $39(70.91)$ & 54 \\
\hline Total & $\mathbf{2 1}$ & $\mathbf{5 5}$ & $\mathbf{7 6}$ \\
\hline
\end{tabular}

Table-3: Showing time duration of surgery.

\begin{tabular}{|c|c|c|c|}
\hline Time(mins) & 3 port & $\mathbf{4}$ port & Number of patients \\
\hline $30-40$ & 0 & 0 & 6 \\
\hline $41-50$ & $3(14.2 \%)$ & $3(5.45 \%)$ & 13 \\
\hline $51-60$ & 0 & $13(23.6 \%)$ & 27 \\
\hline $61-70$ & $17(80.9 \%)$ & $10(18.1 \%)$ & 11 \\
\hline $71-80$ & $1(4.7 \%)$ & $10(18.1 \%)$ & 16 \\
\hline $81-90$ & 0 & $16(29.9 \%)$ & 3 \\
\hline $91-100$ & 0 & $3(5.45 \%)$ & $\mathbf{7 6}$ \\
\hline Total & $\mathbf{2 1}$ & $\mathbf{5 5}$ & \\
\hline
\end{tabular}


Mean duration of surgery is more in Conventional laparoscopic cholecystectomy as compared with the three port laparoscopic cholecystectomy as shown. (Table 3). Mean OT time for three port was 66.90 minute \& for four port it was 75.45 minute. With P-value $=\mathbf{0 . 0 0 0 6}$ obtained using t-test for independent samples.

Table-4: Showing duration of Hospital stay.

\begin{tabular}{|c|c|c|c|}
\hline Hospital Duration (days) & $\mathbf{3}$ port & $\mathbf{4}$ port & Number of patients \\
\hline$<2$ & 0 & 0 & 51 \\
\hline $3-5$ & $18(85.7 \%)$ & $33(60 \%)$ & 23 \\
\hline $6-8$ & $3(14.3 \%)$ & $20(36.3 \%)$ & 1 \\
\hline $9-11$ & 0 & $1(1.8 \%)$ & 1 \\
\hline $12-14$ & 0 & $1(1.8 \%)$ & $\mathbf{7 6}$ \\
\hline
\end{tabular}

Over all hospital stay is less in our three port group than in the four port group because our institute being a tertiary care centre, patients from remote areas who cannot make follow up, are tend to be discharged after suture removal. Mean duration of post-operative stay for three port was 4.66 and for the conventional group it was 5.30. (Table 4)

P-value $=0.0267(S)$ obtained using t-test for independent samples

Mean analgesic requirement for the three port group was 35.42 hours and the mean for conventional group was 43.20 hours. (Table 5) $\mathbf{P}$-value $=\mathbf{0 . 0 0 0 2}$ (S) obtained using t-test for independent samples.

Table-5: Showing postoperative analgesic requirement.

\begin{tabular}{|c|c|c|c|}
\hline Analgesic requirement (hours) & $\mathbf{3}$ port & $\mathbf{4}$ port & Number of patients \\
\hline up to $12 \mathrm{hrs}$ & 0 & 0 & 0 \\
\hline $13-24$ & $2(9.5 \%)$ & $10(18.1 \%)$ & 24 \\
\hline $25-36$ & $18(85.7 \%)$ & $6(10.9 \%)$ & 36 \\
\hline $37-4278$ & $1(4.7 \%)$ & $35(63.6 \%)$ & 4 \\
\hline $49-72$ & 0 & $4(7.27 \%)$ & $\mathbf{7 6}$ \\
\hline Total & $\mathbf{2 1}$ & $\mathbf{5 5}$ & \\
\hline
\end{tabular}

Comparing the visual analogue pain scale scores, 3 port group had 5 patients with a VAS of 7-8 immediately after the surgery whereas not a single patient had any pain score between 7-8 after 24 hours of surgery. While in the 4 port group, 22 patients had a VAS of 7-8 immediately after surgery whereas not a single patient had any pain score between 7-8 after 24 hours of surgery.

Observing the complications postoperatively, only two patients in the four port group developed fever post operatively after 48 hours. Rest all other patients had no complications.

\section{Discussion}

In the era of laparoscopic surgery, less postoperative pain and early recovery are major goals to achieve better patient care and cost effectiveness. Several studies demonstrated that less post-operative pain was associated with reduction in either size or number of ports. The use of fourth trocar is considered unnecessary by some surgeons while few of them used sutures to retract gallbladder fundus.
Gallstone disease is a global health problem. The incidence is $10-20 \%$ of the whole adult population, making laparoscopic cholecystectomy one of the most frequently performed operations in the world.

Most patients are asymptomatic and gallstones are generally detected with ultrasonography during the evaluation of unrelated medical conditions. Over the 
past two decades, Laparoscopic Cholecystectomy has become the gold standard for the surgical treatment of gallbladder disease. A shorter hospital stay and rapid return to normal activity and work, less postoperative pain, a faster recovery and lower cost and better cosmetics are some of the advantages of Laparoscopic Cholecystectomy.

Looking at age incidence our study had the incidence ranging between 21-68 years with Mean of 46.38years. Barbara et al [12] reported prevalence of Gall stones peaking in 50-60 years. Further study of Ranshoff and Gracie [13] concluded similar result. Leon Morgenstern [14] showed maximum age incidence in 6th and 7th decades. This is accordance with observation of Malhotra [15], which suggest that as compared to western countries, Cholelithiasis is more prevalent in younger population in our region [16-19]. In our study 21 patients were males and 55 were females. Females outnumbered males in each age group. The male female ratio in our study is $1: 2.61$ which well compares with the study of Kimura $\mathrm{K}$ et al [20]. This ratio also well compares with the studies by Ganey et al [21] and Leon Morgenstern et al [14] (1992).

All studies indicate that incidence of cholelithiasis is more in females as compared to males. The reasons for increased incidence being presence of estrogen in females, which increases cholesterol secretion in bile and increased intestinal transit time of bile salts which further increases intestinal bile salt absorption Jeffrey et al [22].

Considering the duration of surgery, our study $71 \%$ in the three port and $70 \%$ in the four port fell in the $>70$ minute time span. Three port had a mean time of 66.90 minutes and four port had a mean time of 75.54 minutes. It was also interesting that mean operative time was shorter for three-port technique, which does not correlate with previous studies. [23-24].

One explanation for the shorter operative time in the three -port group is that less time was spent on the establishment and subsequent closure of the additional port. One finding consistently noted in our study was that three port technique was slight difficult to perform with long gallbladder with a long peritoneal fold. This was because the fundus of gall bladder repeatedly fell toward the area of the dissection in calots triangle. This finding was consistent with the study conducted in Nepal by Trichak S [25]
In our study, patients who underwent the three port technique had a mean duration of hospital stay of 4.66 days where as patients who underwent the conventional technique had a mean stay of 5.30 days. $42.86 \%$ of patients were discharged before the 4 th post op day in the 3 port category whereas only $34.55 \%$ of patients were discharged in the 4 port category. These figures were comparable with the study published by Kumar et al [26-27].

In our study postoperative pain was measured by VAS (visual analogue score). Patients who underwent the three port cholecystectomy, $76 \%$ of them had a VAS of $<6$ whereas only $60 \%$ of the four port patients had a VAS of $<6$. The results of three port technique were more favourable in that it reduced pain, so that fewer analgesic injections were needed for pain control. These figures were comparable with the study published by Kumar et al.

$42.9 \%$ of the patients who underwent the three port technique had a VAS of $<6$ after 24 hours of surgery whereas $50.2 \%$ of the patients who had undergone the conventional technique had a VAS of $<6$ after 24 hours after the surgery. The results of three port technique were more favourable in that it reduced pain, so that fewer analgesic injections were needed for pain control. These figures were comparable with the study published by Kumar et al.

In our study not a single patient required analgesics beyond 48 hours in the three port group whereas 4 patients required it longer than 48 hours in the four port group.

Considering the complications, 2 patients from the four port technique group had fever post operatively 48 hours of surgery.

We have experienced the almost same demographic profile as in other studies. The results of three port technique were more favourable in that it reduced pain, so that fewer analgesic injections were needed for pain control. In our study postoperative analgesia requirement was nil in the three port technique after 48 hours. The overall intraoperative complications in our study occurred with almost equal rate with both the techniques $(\mathrm{p}>0.05)$.

The results show that the three port technique yields the same success rate as the four port one. 
We did not had any bile duct injury in any of these groups. Some surgeons have expressed concerns about the safety of the 3-port technique, arguing that it may lead to a higher percentage of the bile duct injuries.

However, bile duct injury can be avoided if the gallbladder is gripped at the infundibulum, retracted laterally, and dissected at the infundibulum-cystic duct junction rather than cystic duct common bile duct junction.

This study has shown comparable results to those of other studies done in the past and has confirmed the safety of the procedure.

Our findings thus suggest that the three port LC technique was not difficult to master and could be safely performed by trained personnel. Conversion to standard four port laparoscopic procedure should be undertaken wherever necessary. The most important aspect of any surgical procedure is its safety and complications.

\section{Conclusion}

It appears that the 3-port laparoscopic cholecystectomy technique is safe and has similar clinical outcomes to those of the conventional 4-port laparoscopic cholecystectomy technique. There appears to be a reduced need for analgesic injections with no obvious increase in bile duct injuries.

3-port laparoscopic cholecystectomy technique can be a viable alternative in the field of minimally invasive laparoscopic cholecystectomy. It is recommended that the surgeon should not hesitate to put fourth port to ensure safe completion of Surgery. The main advantages of the three-port technique are that it causes less pain, less expense and leaves fewer scars.

\section{Funding: Nil, Conflict of interest: None Permission of IRB: Yes}

\section{References}

1. Barbara L, Sama C, Labate AM, Taroni F, Rusticali AG, Festi D, Sapio C, Roda E, Banterle C, Puci A, Formentini F. A population study on the prevalence of gallstone disease: the Sirmione Study. Hepatology. 1987 Sep 1; 7 (5): 913-7. Cuschieri A. Laparoscopic cholecystectomy. J R Coll Surg Edinb 1999; 44: 187-92.
2. Ji W, Li LT, Li JS. Role of laparoscopic subtotal cholecystectomy in the treatment of complicated cholecystitis. Hepatobiliary Pancreat Dis Int. 2006 Nov $15 ; 5$ (4):584-9.

3. Navez B, Mutter D, Russier Y, et al. Safety of laparoscopic approach for acute cholecystitis: retrospective study of 609 cases. World J Surg. 2001; 25:1352-6.

4. Schafer M, Krahenbuhl L, Buchler MW. Predictive factors for the type of surgery in acute cholecystitis. Am J Surg. 2001; 182: $291-7$.

5. Kauvar DS, Braswell A, Brown BD, Harnisch M. Influence of resident and attending surgeon seniority on operative performance in laparoscopic cholecystectomy. J Surg Res. 2006; 132:159-63.

6. Rai R, Sinha A, Rai S: Randomised clinical trial of open versus laparoscopic cholecystectomy in the treatment of acute cholecystitis. Br J Surg. 2005, 92:4449. Br J Surg. 2005; 92:494-9.

7. Nuzzo G, Giuliante F, Persiani R: The risk of biliary ductal injury during laparoscopic cholecystectomy. J Chir (Paris). 2004,141:343-53.

8. Roberto Saintambrogio et al. Technical difficulties and complications during laparoscopic cholecystectomy: Predictive use of ultrasonography. World J. Surg. 20:978- 982,1996.

9. Jagdish Nachnani, Avinash Supe. Preoperative prediction of difficult laparoscopic cholecystectomy using clinical and ultrasonographic parameters. Indian journal of gastroenterology, 2005: 24:16-18.

10. Clavien PA, Sanabria JR, Strasberg SM. Proposed classification of complications of surgery with examples of utility in cholecystectomy. Surgery. 1992 May; 111(5):518-26.

11. Barbara L, Sama C, Morselli Labate AM, Taroni F, Rusticali AG, Festi D, Sapio C, Roda E, Banterle C, Puci A, et al. A population study on the prevalence of gallstone disease: the Sirmione Study. Hepatology. 1987 Sep-Oct;7(5):913-7.

12. Gracie WA,Ranshoff DF The natural History of silent gall stones N. England J. Med; 307 1982:798-800. 
13. Leon Morgenstern AD, Wong L, Berci G: Twelve hundred open cholecystectomies before the laparoscopic era. A standard for comparison. Arch Surg 1992; 127:400-403.

14. S L Malhotra Epidemiological study of cholelithiasis among railroad workers in India with special reference to causation. Gut. 1968 Jun; 9(3): 290-295.

15. Gaharwar A. Factors favouring cholelithiasis in north Indian population. IOSR Journal Of Pharmacy. 2013 Jun; 3(5):01-3.

16. Bansal A, Akhtar M, Bansal AK. A clinical study: prevalence and management of cholelithiasis. IntSurg J. 2014; 1(3): 134-139.

17. Hussain A1, Mahmood HK, Duluk K.Laparoscopic cholecystectomy can be safely performed in a resourcelimited setting: the first 49 laparoscopic cholecystectomies in Yemen. JSLS. 2008 Jan-Mar; 12 (1):71-6.

18. C Palanivelu, Kalpesh Jani, and Gobi S. Mahesh Kumar. Single Center Experience of Laparoscopic CholecystectomyJournal of Laparoendoscopic\& Advanced Surgical Techniques. October 2007, 17(5): 608-614.

19. Kimura K et al. Prospective study of laparoscopic cholecystectomy in two hundred and fifty patients. Endoscopy 1992;24(9)740-4.
20. Ganey JB, Johnson PA Jr, Prillaman PE, McSwain GR. Cholecystectomy: clinical experience with a large series. Am J Surg. 1986 Mar;151(3):352-7.

21. Jeffrey D browning, jaya prakash serenerasimhaiah. Gallstone disease. sleisenger and fordtran's gastro intestinal and liver disease: 8th edition: Saunders Elsevier publication: vol1 chapter 62: 1387-1417.

22. Sun S, Yang K, Gao M, He X, Tian J, Ma B. Threeport versus four-port laparoscopic cholecystectomy: Meta-analysis of randomized clinical trials. World J Surg 2009; 33:1904-8.

23. Slim K, Pezet D, Stencl J Jr, Lechner C, Le Roux S, Lointier P, et al. Laparoscopic cholecystectomy: An original three-trocar technique. World J Surg 1995; 19:394-7.

24. Trichak S. Three-port vs standard four-port laparoscopic cholecystectomy. Surg Endosc. 2003 Sep; 17 (9):1434-6. Epub 2003 Jun 13.

25. Dion YM, Morin J. Laparoscopic cholecystectomy: a report of 60 cases. Canadian journal of surgery. Journal canadien de chirurgie. 1990 Dec; 33(6):483-6.

26. Kumar M, Agrawal CS, Gupta RK. Three-port versus standard four-port laparoscopic cholecystectomy: a randomized controlled clinical trial in a community-based teaching hospital in eastern Nepal. JSLS. 2007 Jul-Sep;11(3):358-62.

27. Harsha H S, Gunjiganvi M, Singh C, Moirangthem G S. A study of three-port versus four-port laparoscopic cholecystectomy. J Med Soc 2013; 27:208-11.

\section{How to cite this article?}

Wilkinson TRV, Mehrotra P, Bansod P, Akhtar M. Three port versus four port laparoscopic cholecystectomy- a prospective study. Int J Med Res Rev 2017;5(03):235-241 doi:10.17511/ijmrr. 2017.i03.04. 